\title{
Heterogeneity and electrolyte adsorption: intrinsic and electrostatic effects
}

\author{
W. H. van Riemsdijk ${ }^{1}$, L. K. Koopal ${ }^{2}$ and J. C. M. de Wit ${ }^{1}$ \\ ${ }^{1}$ Department of Soil Science and Plant Nutrition, Wageningen Agricultural Uni- \\ versity, P.O. Box 8005, NL 6700 EC Wageningen, Netherlands \\ ${ }^{2}$ Department of Physical and Colloid Chemistry, Wageningen Agricultural Uni- \\ versity, P.O. Box 8038, NL 6700 EK Wageningen, Netherlands
}

Received 24 April 1987; accepted 9 June 1987

Key words: metal oxides, humic and fulvic acids, organic colloids, site heterogeneity, electrostatic interactions, surface charge $\mathrm{pH}$ relation, intrinsic-affinity distribution, condensation approximation, apparent-affinity distribution

\begin{abstract}
Adsorption of electrolytes in natural systems is an important phenomenon. Natural systems contain sorbents with a predominantly constant surface charge, such as clay minerals, as well as a complex mixture of mainly variable charge sorbents like organic matter, both in the dissolved and in the soil solid phase, and metal oxides. The effect of a combination of an intrinsic-affinity distribution (both discrete and continuous) and a variable surface potential on adsorption behaviour of protons is discussed both for random and patchwise heterogeneity. It is shown that the variable charge (potential) on intrinsically homogeneous metal oxides and organic model colloids leads to an apparent heterogeneity of binding sites. This effect is quantified with simulated data and the condensation approximation. For heterogeneous charged sorbents, where the apparent affinity represents both the chemical heterogeneity and the electrostatic interactions, very wide apparent-affinity distributions will be found. The apparent-affinity distribution is in general only a poor representation of the intrinsic-affinity distribution.
\end{abstract}

\section{Introduction}

The behaviour of ions in natural systems such as soils and sediments is often determined by the interaction of these ions with clay minerals, metal oxides and natural organic matter. This organic matter may be present both in the soil solid phase and to a lesser extent in the liquid phase as dissolved fulvic or humic acids. The interaction between dissolved ions and the natural reactive 'sorbents' mentioned may be non-specific due to charge compensation in the diffuse double layer and/or ion-specific through specific binding by the reactive groups of the different sorbents. In 
case of specific interaction the extent of binding is also influenced by the electrostatic potential at the place where the ion is adsorbed. In general purely non-specific binding of trace metals in natural systems is of much less importance than the specific binding. This is due to the large excess (typically a factor of $10^{3}-10^{5}$ ) of ions such as $\mathrm{Ca}^{2+}$ and $\mathrm{Na}^{+}$as compared to trace metals such as $\mathrm{Cu}^{2+}$ and $\mathrm{Cd}^{2+}$.

When clay minerals dominate in a soil, the interaction of cations such as $\mathrm{Ca}^{2+}$ and $\mathrm{Na}^{+}$with the soil is mainly determined by ion exchange on the clay minerals. Many different types of clay minerals exist, varying considerably in terms of surface charge density or CEC (see e.g. Greenland \& Hayes, 1978; Sposito, 1984; Bolt \& van Riemsdijk, 1987). The interaction of the commonly occurring cations with the different clay minerals is dominated by the electrical interaction of these ions with the permanently charged sites on the clay minerals. An in-depth analysis of this type of interaction is given in Bolt (1982).

Due to their complex composition, soils and sediments should in general be considered as a heterogeneous collection of adsorption sites. Even individual soil constituents may show a whole range of affinities for adsorption of a given ion, due to the presence of different types of reactive surface groups and due to a varying surface potential. For a better understanding of the interaction of ions with soil it is of interest (1) to analyse the effects which a distribution of intrinsic affinities has on the ion adsorption on variably charged surfaces and (2) to compare the intrinsic-affinity distribution with the apparent-affinity distribution which can be calculated on the basis of the surface charge-pH curves of the studied surfaces. The calculation of apparent-affinity distributions (affinity spectra) to characterize the heterogeneity of organic matter has been suggested by Shuman et al. (1983), Hunston (1975) and others. In this paper the effects of surface heterogeneity and electrostatic interactions on the adsorption of protons on metal oxides, organic matter and organic model colloids will be discussed, together with the apparent distribution functions which result from the charge-pH curves of these materials.

A complementary study has been presented by van Riemsdijk et al. (1986a). The effect of heterogeneity of the chemical composition of the soil on the transport of chemicals on a field scale or regional scale is discussed elsewhere (van der Zee \& van Riemsdijk, 1986).

\section{Heterogeneity and adsorption: General concepts}

Most work regarding adsorption on heterogeneous surfaces can be found in gas adsorption literature. Recent reviews of this subject are given by Jaroniec (1983) and House (1983). The specific interaction between a species $C_{i}^{z}$ in solution with a charge $\mathrm{z}$ and a surface site $\left(\mathrm{S}_{\mathrm{j}}\right)$ with charge $\mathrm{n}$ can be represented as

$$
\mathrm{S}_{\mathrm{j}}^{\mathrm{n}}+\mathrm{C}_{\mathrm{i}}^{\mathrm{z}} \leftrightarrows \mathrm{S}_{\mathrm{j}}^{\mathrm{n}} \mathrm{C}_{\mathrm{i}}^{\mathrm{z}} ; \quad \mathrm{K}_{\mathrm{j} . \mathrm{i}}
$$

with

$$
\mathrm{K}_{\mathrm{j}, \mathrm{i}}=\frac{\left[\mathrm{S}_{\mathrm{j}}^{\mathrm{n}} \mathrm{C}_{\mathrm{i}}^{\mathrm{z}}\right]}{\left[\mathrm{S}_{\mathrm{j}}^{\mathrm{n}}\right]\left[\mathrm{C}_{\mathrm{i}}^{\mathrm{z}}\right]}
$$


where $\mathrm{K}_{\mathrm{j}, \mathrm{i}}$ is the intrinsic affinity between site $\mathrm{j}$ and ion i expressing the non-electrostatic interactions, $\left[\mathrm{C}_{\mathrm{i}}^{\mathrm{z}}\right]$ is the concentration of $\mathrm{C}_{\mathrm{i}}^{\mathrm{z}}$ adjacent to the plane of adsorption, $\left[S_{j}^{n}\right]$ and $\left[S_{j}^{n} C_{i}^{z}\right]$ are site densities. $\left[C_{i}^{z}\right]$ is related to the concentration in the bulk of the solution $\left[\mathrm{C}_{i, b}^{z}\right]$,

$$
\left[\mathrm{C}_{\mathrm{i}}^{\mathrm{z}}\right]=\left[\mathrm{C}_{\mathrm{i}, \mathrm{b}}^{\mathrm{z}}\right] \mathrm{e}^{-\mathrm{zF} \Psi / \mathrm{RT}}
$$

where $\Psi$ is the electric potential at the plane of adsorption. Eq. $1 \mathrm{~b}$ is based on the assumption that lateral non-coulombic interactions can be neglected, it can also be written as

$$
\theta_{\mathrm{j}, \mathrm{i}}=\frac{\mathrm{K}_{\mathrm{j}, \mathrm{i}}\left[\mathrm{C}_{\mathrm{i}}^{2}\right]}{1+\mathrm{K}_{\mathrm{j}, \mathrm{i}}\left[\mathrm{C}_{\mathrm{i}}^{\mathrm{z}}\right]}
$$

where $\theta_{\mathrm{j}, \mathrm{i}}$ is the relative (surface) coverage of sites $\mathrm{j}$ with species $\mathrm{C}_{\mathrm{i}}^{\mathrm{z}}$ given by

$$
\theta_{\mathrm{j}, \mathrm{i}}=\left[\mathrm{S}_{\mathrm{j}}^{\mathrm{n}} \mathrm{C}_{\mathrm{i}}^{\mathrm{z}}\right] /\left[\mathrm{N}_{\mathrm{j}}\right]
$$

where $N_{j}$ is the total site density of site type $j$, which in this case equals $\left[S_{j}^{n} C_{i}^{z}\right]+$ $\left[\mathrm{S}_{\mathrm{j}}^{\mathrm{n}}\right]$.

For homogeneous electrostatic site binding models there is only one type of site $\mathrm{S}_{\mathrm{j}}$ (see for a discussion of these models e.g. Healy \& White, 1978; Westall \& Hohl, 1980; Bolt \& van Riemsdijk, 1987; Koopal et al., 1987.) In the case of a heterogeneous surface there is more than one site type present on the surface, and Eqs. 3 and 4 can be applied for each site type $\mathrm{j}$ present.

The total site density for a heterogeneous sorbent, $\mathrm{N}_{\mathrm{t}}$, is given by

$$
\mathrm{N}_{\mathrm{t}}=\Sigma \mathrm{f}_{\mathrm{j}}^{\mathrm{A}} \mathrm{N}_{\mathrm{j}}
$$

The fraction, $\mathrm{f}_{\mathrm{j}}^{\mathrm{A}}$, of a site type $\mathrm{j}$ with respect to the total surface area is equal to

$$
\mathrm{f}_{\mathrm{j}}^{\mathrm{A}}=\left(\mathrm{N}_{\mathrm{j}} / \mathrm{N}_{\mathrm{i}}\right) \mathrm{f}_{\mathrm{j}}^{\mathrm{s}}
$$

where $f_{j}^{s}$ is the fraction of a site type $j$ with respect to the total number of sites available. The overall total relative surface coverage with species $C_{i}^{z}, \theta_{i, t}$ on all types $j$ equals

$$
\theta_{\mathrm{i}, \mathrm{t}}=\Sigma_{\mathrm{j}} \mathrm{f}_{\mathrm{j}}^{\mathrm{s}} \theta_{\mathrm{j}, \mathrm{i}}
$$

Combination of Eq. 3 and Eq. 7 leads to

$$
\theta_{\mathrm{i}, \mathrm{t}}=\Sigma_{\mathrm{j}} \mathrm{f}_{\mathrm{j}}^{\mathrm{s}}\left\{\mathrm{K}_{\mathrm{j}, \mathrm{i}}\left[\mathrm{C}_{\mathrm{i}}^{\mathrm{z}}\right] /\left(1+\mathrm{K}_{\mathrm{j}, \mathrm{l}}\left[\mathrm{C}_{\mathrm{i}}^{\mathrm{z}}\right]\right)\right\}
$$


If all $\mathrm{f}_{\mathrm{j}}$ 's, $\mathrm{K}_{\mathrm{j}, \mathrm{i}}$ 's and $\mathrm{N}_{\mathrm{t}}$ are known and it is decided how to calculate $\Psi$ (see Eq. 2), then the overall adsorption of ion type $\mathrm{C}_{\mathrm{i}}^{\mathrm{z}}$ on a heterogeneous system can be calculated.

With respect to the calculation of $\Psi$ for a heterogeneous charged surface two extremes can be distinguished. The one extreme is a random heterogeneous surface, where there is only one (smeared out) potential $\Psi$ in the plane of adsorption. The other extreme is a patchwise surface with large patches, where each patch is characterized by its own (smeared out) potential. The last case is equivalent to a heterogeneous mixture of different in itself homogeneous (charged) surfaces (Bolt \& van Riemsdijk, 1987). A more elaborate discussion on this subject is in preparation (Koopal \& van Riemsdijk).

When the difference between the consecutive $\log \mathrm{K}_{\mathrm{j}, \mathrm{i}}$ values is small Eq. 8 may be replaced by an integration and the discrete distribution of $f_{j}$ is replaced by a continuous (energy) distribution function $\mathrm{f}\left[\log \mathrm{K}_{\mathrm{i}}\right]$. The equivalent of Eq. 7 for a continuous distribution function is:

$$
\theta_{i, \mathrm{t}}={ }_{\Delta} \int \theta_{\mathrm{i}} \mathrm{f}\left[\log \mathrm{K}_{\mathrm{i}}\right] \mathrm{d} \log \mathrm{K}_{\mathrm{i}}
$$

where $\Delta$ is the relevant range of integration and $\theta_{\mathrm{i}}$ is given by Eq. 3, omitting subscript $\mathrm{j} \theta_{\mathrm{i}}$ is called the local isotherm. For some special cases it is possible to solve Eq. 9 analytically. One result will be discussed here, the well known Langmuir-Freundlich equation that results from a nearly Gaussian distribution function of $\log \mathrm{K}_{\mathrm{i}}$ (Sips, 1948, 1950; van Riemsdijk et al., 1986b). For a system with one specifically adsorbing component:

$$
\theta_{\mathrm{i}, \mathrm{t}}=\frac{\left(\mathrm{K}_{\mathrm{i}} \mathrm{C}_{\mathrm{i}}^{\mathrm{z}}\right)^{\mathrm{m}}}{1+\left(\mathrm{K}_{\mathrm{i}} \mathrm{C}_{\mathrm{i}}^{\mathrm{z}}\right)^{\mathrm{m}}} \quad 0<\mathrm{m} \leqslant 1
$$

where $m$ determines the width of the distribution function. The integration can only be done for a random heterogeneous surface, i.e. with a smeared out potential that is uniform over the surface as a whole at a given value of $\theta_{\mathrm{i}, \mathrm{t}}$ (van Riemsdijk et al., 1986b). When in a multi-solute system for a given sorbent the shape of the intrinsicaffinity distribution is the same (same value of $\mathrm{m}$ ) for all adsorbing ions then Eq. 11 can be derived (van Riemsdijk et al., 1986, 1987):

$$
\theta_{i, t}=\frac{Y_{i}}{\left\{1+\left(\Sigma Y_{i}\right)^{m}\right\}\left(\Sigma Y_{i}\right)^{1-m}}
$$

where $Y_{i}$ is a composite term made up of a product of one or more of the affinities $\left(\mathrm{K}_{\mathrm{i}}\right)$ and concentrations $\left(\left[\mathrm{C}_{\mathrm{i}}^{\mathrm{z}}\right]\right)$ of the various ions involved in the specific adsorption reaction. The different $Y_{i}$ 's follow from the solution of a set of individual adsorption equations and the choice of a reference surface site.

The condition that the shape of the intrinsic affinity distribution is the same for all adsorbing species (correlation coefficient $=1$ ) is probably reasonable in case of a heterogeneous metal oxide. More general treatments that do not suffer from this 
restriction are also possible. For instance, one can consider a joint Gaussian distribution function (Jaroniec \& Rudzinsky, 1975; Müller et al., 1985). A full evaluation of such a complex model approach for more than two competing species requires a very large and precise set of data. So far such an approach has only been tried for a bivariate Gaussian distribution.

For surfaces with a considerable heterogeneity an advantage of the use of a continuous distribution function over the use of a discrete distribution is the limited number of parameters that is needed to characterize the system $\left(\mathrm{N}_{\mathrm{t}}, \mathrm{K}_{\mathrm{i}}\right.$, and $\mathrm{m}$ versus $N_{t}, A_{t}, n K_{i, j}$ 's, $n-1 f_{j}^{A}$ 's and $n-1 f_{j}^{s}$ 's for $n$ site types $j$ ).

Instead of presuming a certain type of distribution function beforehand (e.g. Eqs. 10 and 11) one can try to establish the distribution function from (single solute) adsorption data using Eq. 8. Several advanced numerical schemes have been developed and applied mainly to gas adsorption data (House \& Jaycock, 1977, 1978; Sacher \& Morrison, 1979; House, 1983; Vos \& Koopal, 1985; Koopal \& Vos, 1985). Application of these procedures to adsorption from solution is thwarted by the experimental error mostly present in such data. Inversion of Eq. 9 with respect to $f\left[\log \mathrm{K}_{\mathrm{i}}\right]$ requires very accurate data because the mathematical solution is ill-conditioned. A discussion of the problems involved in inverting Eq. 9, which is a socalled Fredholm equation of the first kind, has been given by Noble (1977).

Apart from these optimization techniques, approximate methods which do not suffer from instabilities have been developed to estimate the distribution function on the basis of available adsorption data. The most simple method is the so called 'condensation approximation' (CA). The CA method is originally developed for gas adsorption (Harris, 1968, 1969a, b) and is discussed by Cerofolini (1974). In the $\mathrm{CA}$ method the local isotherm (see Eq. 3 ) is approximated by a step function. The relative local surface coverage $\left(\theta_{\mathrm{j}, \mathrm{i}, \mathrm{CA}}\right)$ is thus either zero or one:

$$
\theta_{\mathrm{j}, \mathrm{i}, \mathrm{CA}}=\mathrm{H}\left[\mathrm{C}_{\mathrm{i}}^{\mathrm{z}}-\mathrm{C}_{\mathrm{C}, \mathrm{i}}^{\mathrm{z}}\right]
$$

Eq. 12 is a Heavyside function (Papoulis, 1972). $\mathrm{H}[\mathrm{P}] \equiv 0$ for $\mathrm{P}<0$ and $\mathrm{H}[\mathrm{P}] \equiv$ 1 for $P \geqslant 0,\left[C_{C, i}^{Z}\right]$ is the critical concentration where the coverage changes from zero to one. If, for instance, the Langmuir isotherm is chosen as local isotherm, $\left(\mathrm{C}_{\mathrm{C}, \mathrm{i}}^{\mathrm{z}} \mathrm{]}\right.$ is related to the situation where $\theta_{\mathrm{i}}=0.5$ leading to

$$
-\log \left[\mathrm{C}_{\mathrm{C}, \mathrm{i}}^{\mathrm{z}}\right]=\left[\log \mathrm{K}_{\mathrm{i}}\right]_{\mathrm{CA}}
$$

In literature on humic acids an equivalent procedure is known as the 'affinity spectrum technique' (Shuman et al., 1983; Dzombak et al., 1986). In the CA method the distribution function $f\left[\log \mathrm{K}_{\mathrm{i}}\right]_{\mathrm{CA}}$ results by differentiating the amount adsorbed with respect to the logarithm of the concentration in solution.

$$
\mathrm{f}\left[\log \mathrm{K}_{\mathrm{i}}\right]_{\mathrm{CA}}=-\left\{\left(\frac{\partial \theta_{\mathrm{i}, \mathrm{t}}}{\partial \log \left[\mathrm{C}_{\mathrm{i}}^{\mathrm{z}}\right]}\right)\left(\frac{\partial \log \left[\mathrm{C}_{\mathrm{i}}^{\mathrm{z}}\right]}{\partial \log \mathrm{K}_{\mathrm{i}}}\right)\right\}_{\left[\mathrm{C}_{\mathrm{i}}^{\mathrm{z}}\right]=\left[\mathrm{C}_{\mathrm{C}, \mathrm{i}}^{\mathrm{z}}\right]}
$$

Application of Eq. 14 to an analytical overall isotherm such as Eq. 10 results in an 
analytical expression for the CA distribution function. This approximated distribution function can now be compared with the real distribution function underlying Eq. 10. It turns out (van Riemsdijk et al., 1986a) that the CA method leads to a very good approximation when the real distribution function is wide (small values of $\mathbf{m}$ ) and to a too wide (approximated) distribution when $\mathrm{m}$ is close to one.

\section{Metal oxides}

\section{Homogeneous metal oxide}

The surface charge of a homogeneous metal oxide can be described with a 'one-pK' model. The use of a single-pK value to describe surface charge-pH curves for metal oxides has first been proposed by Bolt \& van Riemsdijk (1982). Recently it has been shown that the one-pK model can indeed simulate $\sigma_{\mathrm{o}} \mathrm{pH}$ curves for $\mathrm{TiO}_{2}$ (van Riemsdijk et al., 1986b), for iron oxides (van Riemsdijk et al., 1987) and for $\mathrm{A}_{2} \mathrm{O}_{3}$ and $\mathrm{A} 1(\mathrm{OH})_{3}$ (Hiemstra et al., 1987). The model can easily be extended to describe specific adsorption of heavy metals (van Riemsdijk et al., 1987) and anions (van Riemsdijk \& van der Zee, 1986).

The basic assumption of the one-pK model is that the reactive sites on the surface of a metal oxide consist of singly coordinated oxygen atoms. These reactive oxygens may exist either in the form of $\mathrm{SOH}^{1 / 2-}$ or $\mathrm{SOH}_{2}^{1 / 2+}$ (see Fig. 1a). At the pristine point of zero charge (PPZC) the ratio of $\mathrm{SOH}^{1 / 2-}: \mathrm{SOH}_{2}^{1 / 2+}=1: 1$. This can be compared with the situation for a dissolved metal species like $\mathrm{Fe}(\mathrm{OH})_{3}\left(\mathrm{H}_{2} \mathrm{O}\right)_{3}^{\circ}$, usually represented as $\mathrm{Fe}(\mathrm{OH})_{3}^{\circ}$ (see Fig. 1b). The equation relating the two surface sites is

$$
\begin{aligned}
& \mathrm{SOH}^{1 / 2-}+\mathrm{H}^{+} \leftrightarrows \mathrm{SOH}_{2}^{1 / 2+} \\
& \mathrm{K}_{\mathrm{H}}=\frac{\left[\mathrm{SOH}_{2}^{1 / 2+}\right]}{\left[\mathrm{SOH}^{1 / 2-}\right]\left[\mathrm{C}_{\mathrm{H}}^{+}\right]}
\end{aligned}
$$

where $\mathrm{K}_{\mathrm{H}}$ is the intrinsic affinity, $\left[\mathrm{SOH}_{2}^{1 / 2+}\right]$ and $\left[\mathrm{SOH}^{1 / 2-}\right]$ are the site densities and $\left(\mathrm{C}_{\mathrm{H}}^{+}\right]$is the proton concentration at the plane of adsorption, related to its bulk concentration by Eq. 2 .

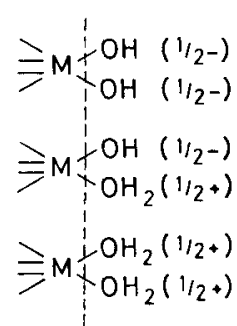

(a)

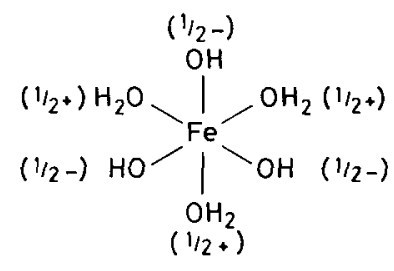

(b)

Fig. 1. Schematic representation of the (uncharged) metal oxide surface (a) compared with (neutral) dissolved iron hydroxide, $\mathrm{Fe}(\mathrm{OH})_{3}\left(\mathrm{H}_{2} \mathrm{O}\right)_{3}^{\circ}(\mathrm{b})$. 
Eq. 15 can be seen as a special case of Eq. 1 where $n=-0.5$ and $z=+1$. The values of $\mathrm{n}$ and $\mathrm{z}$ determine the relationship between $\theta_{\mathrm{i}}$ and the surface charge density. The general expression for the surface charge density based on Eq. 1 is (omitting the subscript $j$ because we are dealing now with a homogeneous surface):

$$
\sigma_{\mathrm{o}}=\mathrm{N}_{\mathrm{t}} \mathrm{F}\left\{(\mathrm{n}+\mathrm{z}) \theta_{\mathrm{i}}+\mathrm{n}\left(1-\theta_{\mathrm{i}}\right)\right\}
$$

For $\mathrm{n}=0.5$ and $\mathrm{z}=+1$, Eq. 16 can be written as

$$
\sigma_{\mathrm{o}}=\mathrm{N}_{\mathrm{t}} \mathrm{F}\left(\theta_{\mathrm{H}}-0.5\right)
$$

The isotherm equation for the protons $\theta_{\mathrm{H}}$ is given by Eq. 3. For the description of heterogeneous metal oxides the general concepts explained in the former section can be applied.

\section{Apparent-affinity distribution for a charged homogeneous metal oxide}

The separation of the free energy of adsorption in an electrical and an intrinsic (chemical) part as done above (see Eqs. 1 and 2), is quite common but arbitrary. Not splitting the affinity in an electrical and a chemical term leads to series of apparent-affinity constants, because the total affinity depends on the value of the surface potential. For instance, in the case of proton adsorption Eq. 15b can be expressed as

$$
\mathrm{K}_{\mathrm{H} . \mathrm{app}} \equiv \mathrm{K}_{\mathrm{H}} \exp (-\mathrm{F} \Psi / \mathrm{RT})=\frac{\left[\mathrm{SOH}_{2}^{1 / 2+}\right]}{\left[\mathrm{SOH}^{1 / 2}\right]\left[\mathrm{C}_{\mathrm{H}, \mathrm{b}}^{+}\right]}
$$

where $\mathrm{K}_{\mathrm{A} \text {.app }}$ is the apparent-affinity constant. Because $\mathrm{K}_{\mathrm{H} \text {,app }}$ varies during a titration, a distributon of $\log \mathrm{K}_{\mathrm{H} \text {,app }}$ values results.

To illustrate this situation simulated proton adsorption data based on the one-pK model combined with a simple Stern-Gouy-Chapman double layer can be used. In Fig. 2A a simulated titration curve is shown for a hypothetical metal oxide with log $\mathrm{K}_{\mathrm{H}}=7\left(=\mathrm{pH}_{\mathrm{PPZC}}\right)$, a Stern layer capacitance of $5 \mathrm{~F} / \mathrm{m}^{2}$, a site density of 8 sites $/ \mathrm{nm}^{2}$ and an ionic strength of $0.5 \mathrm{M}$. The apparent-affinity distribution that results from this curve can be approximated by using the CA method. The result is shown in Fig. 2B. The width of the apparent-affinity distribution found with the CA method has by definition a spread in $\log \mathrm{K}_{\mathrm{H} \text {.app }}$ that is the same as the $\mathrm{pH}$ range of the titration curve going from $\theta_{\mathrm{H}}=1$ (maximum positive surface charge) to $\theta_{\mathrm{H}}=0$ (maximum negative surface charge). The distribution function consists of two mirror images around the PPZC. Hence, although the generated titration curve is based on a homogeneous one-pK model, a bimodal distribution function, $\mathrm{f}\left[\mathrm{K}_{\mathrm{H}, \text { app }}\right]$, is obtained due to the fact that the overall surface charge can become either positive, zero, or negative.

Since the shape of the $\sigma_{\mathrm{o}}$ - $\mathrm{pH}$ curve is a function of the salt level, the resulting distribution function of $\log \mathrm{K}_{\mathrm{H} \text {.app }}$ is also dependent on the salt concentration. For instance, for a lower salt concentration the distribution function will be wider than the 

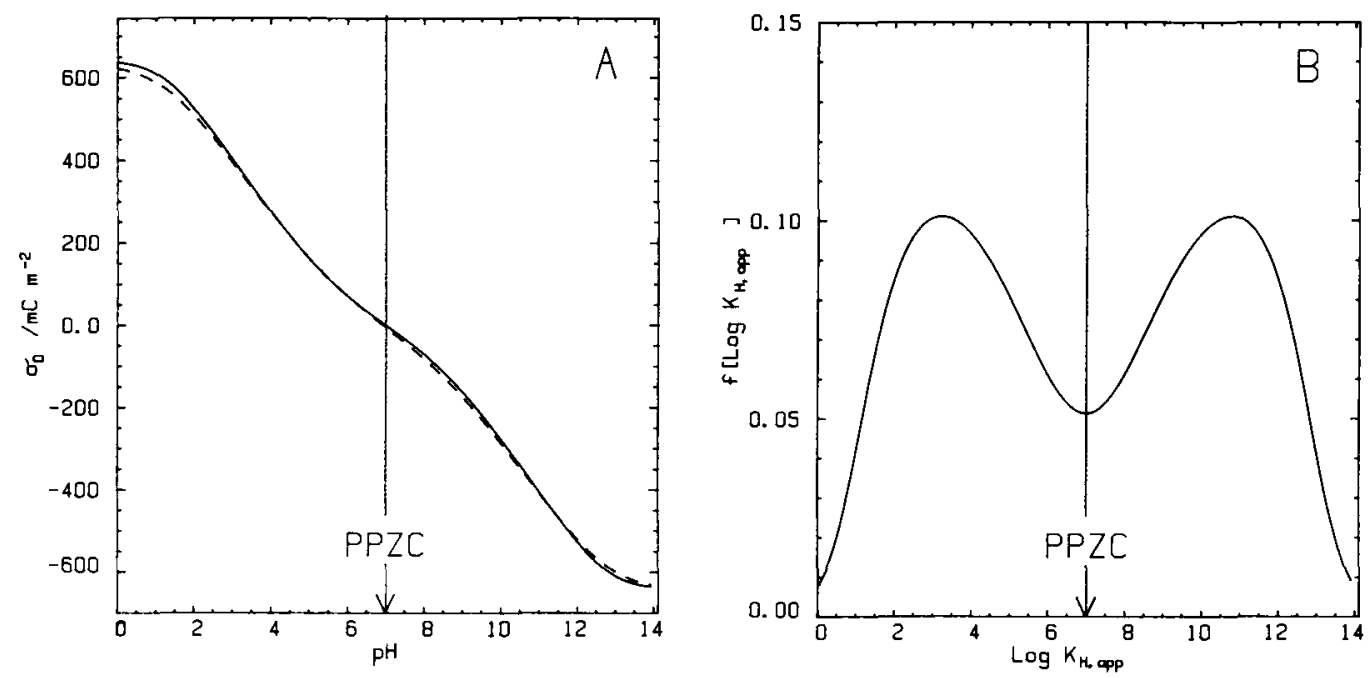

Fig. 2A. Surface charge density versus $\mathrm{pH}$ for a hypothetical homogeneous metal oxide simulated with the one-pK model in combination with the SGC double layer model (solid curve). The parameter values used are: $\log \mathrm{K}_{\mathrm{H}}=7, \mathrm{C}=5 \mathrm{~F} / \mathrm{m}^{2}, \mathrm{~N}_{\mathrm{t}}=8$ sites $/ \mathrm{nm}^{2}$, ionic strength $0.5 \mathrm{M}$.

The dashed curve represents the $\sigma_{\mathrm{o}}$-pH curve reconstructed on the basis of Eqs. 9, 18 and the apparent-affinity distribution function shown in Fig. 2B.

Fig. 2B. The apparent-affinity distribution function $\mathrm{f}\left[\log \mathrm{K}_{\mathrm{H} \text {,app }}\right]$, derived from the $\sigma_{\mathrm{o}}-\mathrm{pH}$ titration curve shown in Fig. 2A with the CA method.

one shown in Fig. 2B. Note that a rather high salt concentration is used in the calculation.

Due to the relatively high site density, high values of the surface potential will develop at high surface charges. Therefore, in normal practice only a relatively small fraction of the total surface groups can be titrated and consequently only a fraction of the total apparent-affinity distribution function can be obtained with the CA method.

On the basis of the obtained (approximate) distribution function of $\log \mathrm{K}_{\mathrm{H} \text {,app }}$ the titration curve can be reconstructed by using Eq. 9 with Eq. 18 as local isotherm. The result is shown in Fig. $2 \mathrm{~A}$ as the dashed line, it can be seen that the resulting $\sigma_{\mathrm{o}}$ $\mathrm{pH}$ curve approximates the original curve quite well. This is in accordance with the general observation that the CA method results in a good approximation for relatively wide distribution functions.

Concluding this section: for an amphoretic surface, based on the one-pK model, the strong electrostatic interactions lead to a very wide distribution of $\log \mathrm{K}_{\mathrm{H} \text {,app }}$ containing two separate peaks.

The CA method gives a reasonable approximation of the distribution of log $\mathrm{K}_{\mathrm{H} \text {.app, }}$, but this distribution has very little in common with the intrinsic-affinity distribution (a delta function). The minimum in the distribution of $\log \mathrm{K}_{\mathrm{H} \text {,app }}$ corresponds with $\log \mathrm{K}_{\mathrm{H}}$. 


\section{Combination of site heterogeneity and electrical effects}

In practice a metal oxide surface may be characterized by a range of different intrinsic affinity constants. The surface heterogeneity may arise from surface defects, the presence of different crystal planes, different surface groups, etc. The titration curve that results for such a heterogeneous metal oxide is thus affected by the distribution of $\mathrm{K}_{\mathrm{H} \text {.intrinsic }}$ as well as by the coulombic interactions.

For a random heterogeneous surface with a uniform surface potential, in combination with a continuous distribution of $\log \mathrm{K}_{\mathrm{H}}$, it has been shown (van Riemsdijk et al., 1986b) that the shape of the titration curve is hardly affected by the distribution of $K_{H \text {,intrinsic }}$ irrespective of the type or width of the distribution function. The main effect may be a shift in the overall PZC (point of zero charge) of the titration curve.

For a patchwise heterogeneous surface, where each patch has its own surface potential (not influenced by the other patches) both the PZC and the shape of the curves are affected (van Riemsdijk et al., 1986a; Bolt \& van Riemsdijk, 1987). When it is assumed that the Stern layer capacitance is the same for all patches it can be shown (Bolt \& van Riemsdijk, 1987) that there is only a common intersection point (CIP) of the overall titration curves at different salt concentration when the intrinsic affinity distribution is symmetrical. This CIP then corresponds with the overall PZC.

In Fig. 3 the overall $\sigma_{\mathrm{o}}$-pH curves of a symmetrical patchwise heterogeneous sur-

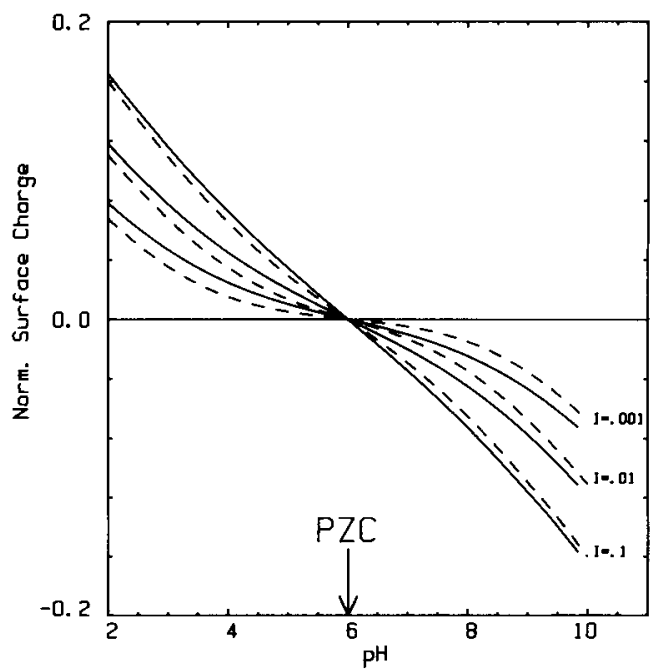

Fig. 3. The overall $\sigma_{0}-\mathrm{pH}$ curves at three different salt concentrations for a patchwise heterogeneous surface composed of seven patches distributed symmetrical around the PZC (solid lines) and for a comparable homogeneous surface (dashed lines).

For both surfaces $\mathrm{pH}(\mathrm{PZC})=6, \mathrm{~N}_{\mathrm{t}}=12$ sites $/ \mathrm{nm}^{2}$ and $\mathrm{C}=1.3 \mathrm{~F} / \mathrm{m}^{2}$ (in the heterogeneous case for each patch). The composition of the heterogeneous surface is:

$\begin{array}{lrrrrrrr}\mathrm{f}_{\mathrm{j}}^{\mathrm{A}} & 0.05 & 0.1 & 0.2 & 0.3 & 0.2 & 0.1 & 0.05 \\ \mathrm{pH}(\mathrm{PZC})=\log \mathrm{K}_{\mathrm{j}, \mathrm{H}} & 3 & 4 & 5 & 6 & 7 & 8 & 9\end{array}$


face composed of seven patches at three different salt concentrations (solid lines) is compared with a homogeneous surface with the same PZC as that of the mixture (dashed lines). For the homogeneous surface and for each patch the one-pK model in combination with the SGC model is used. The Stern layer capacitance, C, is assumed to be $1.3 \mathrm{~F} / \mathrm{m}^{2}$ for all patches and the homogeneous surface. For both cases $\mathrm{pH}(\mathrm{PZC})=6$ and $\mathrm{N}_{\mathrm{t}}=12$ sites $/ \mathrm{nm}^{2}$. The distribution of sites of the heterogeneous surface is given in the captions of Fig. 3. The normalized surface charge density is calculated according to

$$
\sigma_{\mathrm{o}, \text { norm }}=\Sigma \mathrm{f}_{\mathrm{j}}^{\mathrm{A}} \sigma_{\mathrm{o}, \mathrm{j}} /\left(0.5 \mathrm{~N}_{\mathrm{t}} \mathrm{F}\right)
$$

where $0.5 \mathrm{~N}_{\mathrm{t}} \mathrm{F}$ is the maximum absolute surface charge corresponding with the onepK metal oxide model (see Eq. 17). From Fig. 3 it follows that in this case the heterogeneity leads to a higher (absolute) surface charge than for the corresponding homogeneous surface at all $\mathrm{pH}$ values (apart from PZC). The same distribution in combination with a random surface heterogeneity leads to curves that can hardly be distinguished from the homogeneous situation.

In Fig. 4 a result is presented for an asymmetric patchwise distribution. As before the one-pK SGC model with $\mathrm{C}=1.3 \mathrm{~F} / \mathrm{m}^{2}$ (for each patch) and $\mathrm{N}_{\mathrm{t}}=12 \mathrm{sites} / \mathrm{nm}^{2}$ has been used. The PPZC of the homogeneous surface equals 6.36. Fig. 4 clearly shows

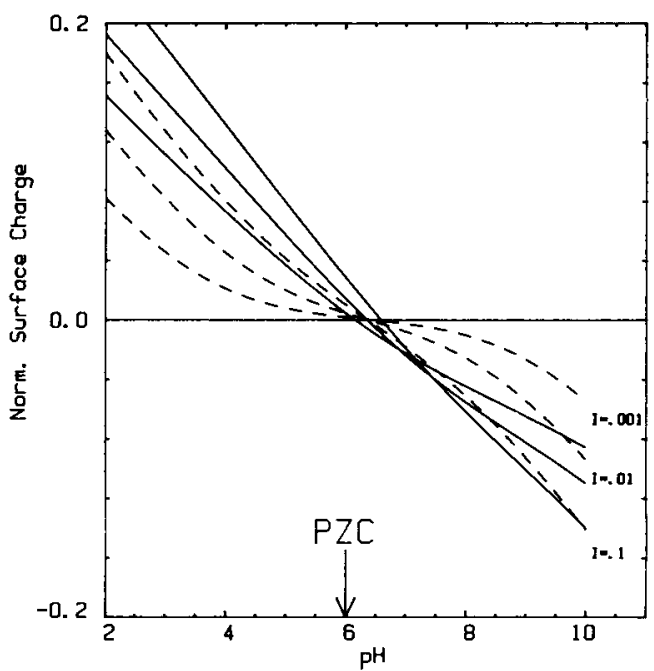

Fig. 4. The $\sigma_{\mathrm{o}}-\mathrm{pH}$ curves at three different salt concentrations for an asymmetric patchwise heterogeneous surface composed of two patches (solid lines) and for a homogeneous surface with a comparable PZC (6.36) (dashed curves).

For both surfaces $\mathrm{N}_{\mathrm{t}}=12$ sites $/ \mathrm{nm}^{2}$ and for all homogeneous patches $\mathrm{C}=1.3 \mathrm{~F} / \mathrm{m}^{2}$. The composition of the heterogeneous surface equals:

$\begin{array}{lrr}\mathrm{f}_{\mathrm{i}}^{\mathrm{A}} & 0.3 & 0.7 \\ \mathrm{pK}_{\mathrm{j}, \mathrm{H}} & 2 & 9\end{array}$ 
that the overall PZC of the mixture (solid lines) is now a function of the salt level with an apparent (approximate) common intersection point at a somewhat negative overall surface charge. This approximate CIP should not be confused with the PZC. The dashed curves are for a homogeneous surface with a PPZC that equals the average PZC of the three curves for the heterogeneous surface. It thus follows that the shape of the curves for the patchwise heterogeneous system differ markedly from the homogeneous situation.

Similarly as shown for the homogeneous metal oxide surface the titration curves can be used to obtain apparent-affinity distribution functions using the CA method. The apparent affinity is in this case due to both the heterogeneity and the electrical effects. For the moment it suffices to note that the $\sigma_{\mathrm{o}}$-pH curves for the heterogeneous surfaces (the solid lines) are rather smooth due to the superposition of the electrical interactions on the heterogeneity. Evidently if smooth $\sigma_{\mathrm{o}}$-pH curves are used to calculate $f\left[\log \mathrm{K}_{\mathrm{H} \text {.app }}\right]_{\mathrm{CA}}$ a smooth distribution results and the discrete nature of the patches is not easily recognized in the apparent-affinity distribution function. Hence, it is to be expected that also here $f\left[\log \mathrm{K}_{\mathrm{H} \text {.app }}\right]_{\mathrm{CA}}$ shows two peaks due to the amphoretic nature of the surface and that the obtained distribution function is not resembling the intrinsic-affinity distribution.

\section{Humic and fulvic acids}

Soil or aquatic organic matter can be seen as a natural polymer consisting of many different building blocks, leading to a large variety of reactive groups. For instance for fulvic acids at least seven amino acids which together amount to 6 to 9 weight $\%$ of the fulvic acid, two hexosamines ( 5 to $14 \%$ ) and six different neutral carbohydrates (10 to $12 \%$ ) have been described as 'building blocks' (Holtzclaw et al., 1980). Only a minor fraction (21-35\%) of the fulvic acid has thus been identified. The negative charge of natural organic matter arises from dissociation of the different acid functional groups, whereas positive charges may originate from basic functional groups. For both types of groups the reaction of a proton with these groups can be written according to Eq. 1. The value of $n$ may be -1 (acidic group) or zero (alkaline group). Because some of these groups have a very high affinity for protons, it is difficult to establish the total number of reactive sites from titration in a non-aqueous solution. However, according to Ephraim et al. (1986) it is possible to estimate the relative presence of these high-affinity sites by titration in a nonaqueous solution, and/or by titration in the presence of complexing metal ions $\left(\mathrm{Cu}^{2+}, \mathrm{Eu}^{3+}\right)$ that are capable of replacing these tightly bound protons. A direct calculation of the net charge of the organic molecule based on $\theta_{\mathrm{H}}$ values is impossible because the value of $n$ in Eq. 1 is not the same for all reactive groups. According to Ephraim et al. (1986) the intrinsic affinity constants of the proton for humic matter range from as low as $\log \mathrm{K}_{\mathrm{H}}=1.8$ to as high as $\log \mathrm{K}_{\mathrm{H}}=13$.

Like in the case of metal oxides, humic materials have a $\mathrm{pH}$-dependent (but predominantly negative) 'surface' charge, giving rise to an electrostatic interaction contributing to the free energy of binding. The binding of ions to humic matter is thus also the result of a combination of electrical and chemical interactions. A dif- 
ference with the metal oxide behaviour is that the electrostatic interaction may also be affected by the spatial conformation of the organic polyelectrolyte, which is a function of $\theta_{\mathrm{H}}$.

In addition to the complexity of one specific macromolecule, in nature one is confronted with a complex mixture of different types of these macromolecules varying in size and relative content of the different reactive groups. Model descriptions for these very complicated systems have so far been mainly of an empirical nature (Sposito, 1987). Recently it has been suggested (Harding \& Healy, 1985) that colloidal latex particles which have carboxylic and amine groups as reactive sites can be considered as an idealized model colloid to represent the complex natural organic matter. Following this line of thinking it is useful to analyse theoretically such simplified 'organic model colloids' in order to assess the relative importance of site heterogeneity and electrical effects in these systems. The effects appearing for these idealized models will basically also be present in more complex natural organic systems. As the behaviour of the humic materials is predominantly governed by the acid groups we restrict ourselves for the moment to calculations for organic model colloids with acid groups only.

\section{Organic model colloids}

\section{Homogeneous organic model colloid}

A simple rigid homogeneous acid organic model colloid in solution can be characterized by one intrinsic affinity $K_{H}$ (Eq. 1 with $n=-1$ and $z=+1$ ) and a SternGouy-Chapman double layer. The expression for the surface charge follows from Eq. 16. The maximum site density $\mathrm{N}_{\mathrm{t}}$ is set at a much lower value than for the metal oxides, in combination with a high value of the Stern layer capacitance $\mathrm{C}$, because it is believed that for natural organic matter sites with a value of $\log \mathrm{K}_{\mathrm{H}}$ that is not too high can be titrated completely in an aqueous medium (Ephraim et al., 1986). The $\sigma_{o}$ - $\mathrm{HH}$ curve of such a model colloid with $\mathrm{N}_{\mathrm{t}}=2 \mathrm{sites} / \mathrm{nm}^{2}$ and $\mathrm{C}=5 \mathrm{~F} / \mathrm{m}^{2}$ in $0.5 \mathrm{M}$ electrolyte is given in Fig. 5A. The effect of the surface potential on the dissociation can be seen because in the absence of the electric field the surface charge should be one half of the maximum surface charge at $\mathrm{pH}=\log \mathrm{K}_{\mathrm{H}}$. The actual ratio is only 0.14 at $\mathrm{pH}=4$. The dissociation is considerably retarded because of the build up of the negative surface potential going from low to high $\mathrm{pH}$.

\section{Apparent-affinity distribution for a charged homogeneous organic colloid}

In the same way as was done for the homogeneous metal oxide system, the approximate apparent-affinity distribution, $\mathrm{f}\left[\log \mathrm{K}_{\mathrm{H}, \mathrm{app}}\right]_{\mathrm{CA}}$, can be calculated from the simulated $\sigma_{\mathrm{o}}-\mathrm{pH}$ curve with the CA method. The result is shown in Fig. 5B. The distribution function is somewhat asymmetric and rather wide. The largest part of the distribution appears for $\mathrm{pH}>4$ as expected on the basis of the $\sigma_{\mathrm{o}}$-pH curve. It should be noted that even for the low value of $N_{1}$ and the high value of $\mathrm{C}$ - representative for relatively weak electrostatic interactions - the distribution function of $\log \mathrm{K}_{\mathrm{H} \text {,app }}$ ranges from about $\mathrm{pH}=1$ to $\mathrm{pH}=10$. The peak of the apparent-affinity distribution is not corresponding with $\log \mathrm{K}_{\mathrm{H}}$ due to the electrostatic interaction. Hence it is 

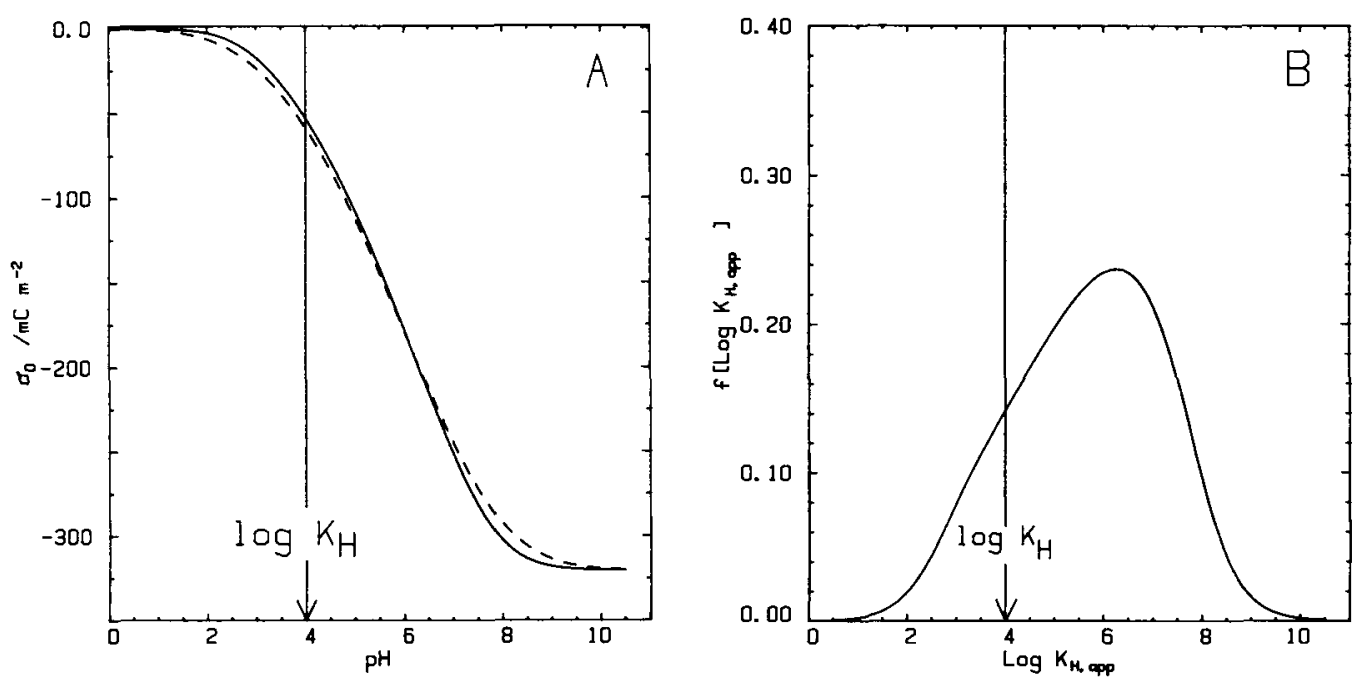

Fig. 5A. The $\sigma_{\mathrm{o}}-\mathrm{pH}$ curve for a homogeneous organic model colloid (solid line). The calculations are based on the one-pK SGC model with $\log K_{H}=4, C=5 \mathrm{~F} / \mathrm{m}^{2}, \mathrm{~N}_{\mathrm{t}}=2 \mathrm{sites} / \mathrm{mn}^{2}$ and I $=0.5 \mathrm{M}$.

The dashed curve represents the titration curve reconstructed on the basis of Eqs. 9, 18 and the apparent-affinity distribution function shown in Fig. 5B.

Fig. 5B. The apparent-affinity distribution function $\mathrm{f}\left[\log \mathrm{K}_{\mathrm{app}, \mathrm{H}}\right]$ derived from the $\sigma_{\mathrm{o}}$-pH curve shown in Fig. $5 \mathrm{~A}$ with the $\mathrm{CA}$ method.

rather difficult to substract information regarding $\log \mathrm{K}_{\mathrm{H}}$ from $\mathrm{f}\left[\mathrm{K}_{\mathrm{H}, \mathrm{app}}\right]_{\mathrm{CA}}$.

On the basis of Eqs. 9 and 18 and the CA distribution function of $\log \mathrm{K}_{\mathrm{H} . \text { app }}, \theta_{\mathrm{H}, \mathrm{t}}$ and hence the $\left(\sigma_{\mathrm{o}}\right)_{\mathrm{CA}}-\mathrm{pH}$ curve can be calculated. As expected on the basis of the range of $\mathrm{K}_{\mathrm{H} \text {.app }}$ values the original $\sigma_{\mathrm{o}}$ - $\mathrm{pH}$ curve is approximated reasonably well, compare the solid and the dashed curve in Fig. 5a.

\section{Combination of site heterogeneity and electrical effects}

In this section the behaviour of heterogeneous organic model colloids will be compared with that of a homogeneous organic colloid. For brevity the combination of a continuous intrinsic-affinity distribution with a uniform smeared out potential will be considered only. This is done by using Eq. 10 and the SGC double-layer model with $\log \mathrm{K}_{\mathrm{H}}=4, \mathrm{C}=5 \mathrm{~F} / \mathrm{m}^{2}$ and $\mathrm{N}_{\mathrm{t}}=2$ sites $/ \mathrm{nm}^{2}$. In Fig. $6 \mathrm{~A}$ the resulting titration curves for a salt concentration of $0.5 \mathrm{M}$ are shown for various values of $m$ (width of intrinsic-affinity distribution). The curve $m=1$ corresponds with the homogeneous surface shown in Fig. 5A,B.

In contrast with the situation for the amphoteric metal oxide where the combination of a continuous intrinsic-affinity distribution and a smeared out potential hardly influences the shape of the $\sigma_{\mathrm{o}}-\mathrm{pH}$ curves, the present curves are relatively sensitive to the width of the intrinsic-affinity distribution function. For a negative (or positive) surface the effect of introducing a symmetrical distribution of affinities around $\log \mathrm{K}_{\mathrm{H}}$ is to decrease the slope of the $\sigma_{\mathrm{o}}-\mathrm{pH}$ curves. The form of Eq. 10 pre- 

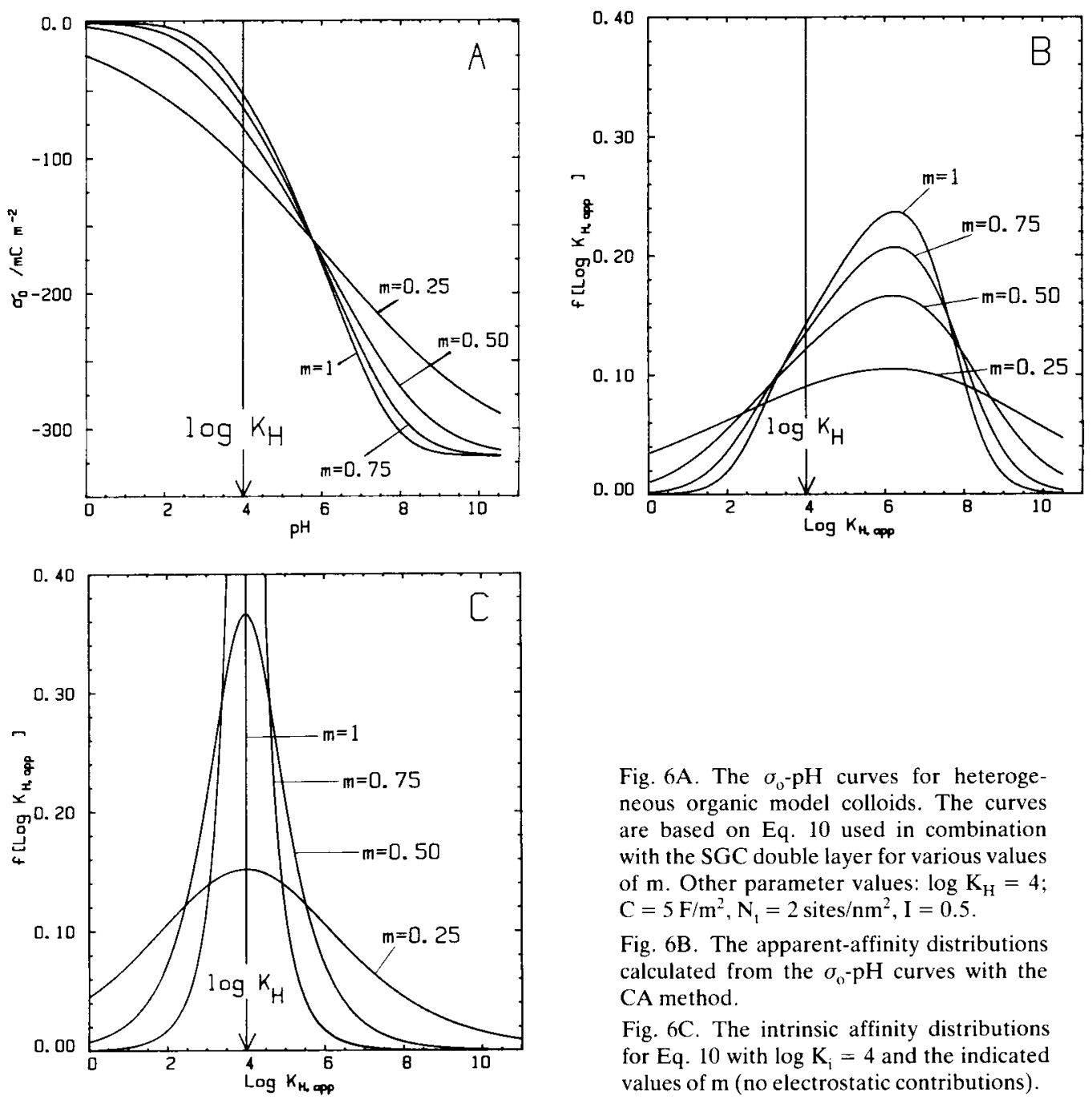

Fig. 6A. The $\sigma_{0}-\mathrm{pH}$ curves for heterogeneous organic model colloids. The curves are based on Eq. 10 used in combination with the SGC double layer for various values of $\mathrm{m}$. Other parameter values: $\log \mathrm{K}_{\mathrm{H}}=4$; $\mathrm{C}=5 \mathrm{~F} / \mathrm{m}^{2}, \mathrm{~N}_{1}=2$ sites $/ \mathrm{nm}^{2}, \mathrm{I}=0.5$.

Fig, 6B. The apparent-affinity distributions calculated from the $\sigma_{0}-\mathrm{pH}$ curves with the CA method.

Fig. 6C. The intrinsic affinity distributions for Eq. 10 with $\log K_{i}=4$ and the indicated values of $m$ (no electrostatic contributions).

dicts that the $\sigma_{\mathrm{o}}-\mathrm{pH}$ curves intersect at $\theta_{\mathrm{H}}=0.5$. In the absence of electrostatic interactions the $\mathrm{pH}$ of this common intersection point corresponds with $\log \mathrm{K}_{\mathrm{H}}$. In the present case $\mathrm{pH}_{\mathrm{ClP}}$ equals $\log \mathrm{K}_{\mathrm{H} \text {.app }}$ and hence the distance between $\mathrm{pH}_{\mathrm{ClP}}$ and $\log$ $\mathrm{K}_{\mathrm{H}}$ is a measure of the electrostatic interactions (see Eq. 18).

Based on each of the curves of Fig. 6A the distribution of $\log \mathrm{K}_{\mathrm{H} \text {,app }}$ can be calculated using the CA method for each value of $\mathrm{m}$. Each obtained distribution function (Fig. 6B) is the result of the combined effect of the intrinsic-affinity distribution on which Eq. 10 is based and the electrostatic effect.

As expected on the basis of the CIP in the $\sigma_{0}-\mathrm{pH}$ curves the peak position of the apparent-affinity distributions is around $\mathrm{pH}=6$. For sake of comparison in Fig. $6 \mathrm{C}$ 
the distribution functions of the intrinsic affinities are shown. As required these curves have their maximum at $\log K=4$, and they are symmetrical. The $\log \mathrm{K}_{\mathrm{H} \text {,app }}$ distributions (Fig. 6B) are asymmetrical due to the fact that at low values of $\sigma_{0}$ an increase in $\sigma_{0}$ has a relatively large effect on $\Psi$ whereas at high values of $\sigma_{0}$ a comparable increase of $\sigma_{\mathrm{o}}$ has only a small effect on the electrostatic potential. By comparing Fig. $6 \mathrm{~B}$ and Fig. $6 \mathrm{C}$ it can be seen that the relative contribution of the electrostatic potential to the distribution of $\log \mathrm{K}_{\mathrm{H} \text {,app }}$ diminishes when the intrinsic distribution widens (i.e. decreasing values of $\mathrm{m}$ ). Hence, for strongly heterogeneous surfaces the apparent-affinity distribution may give some indication of the intrinsic heterogeneity. However, the position of the peak of $f\left[\log \mathrm{K}_{\mathrm{H} . \mathrm{app}}\right]_{\mathrm{CA}}$ is displaced relative to $\log \mathrm{K}_{\mathrm{H}}$ and even for relatively weak electrostatic interactions this displacement is considerable.

\section{Conclusions}

- The condensation approximation is a simple method to determine the apparentaffinity distribution for systems with variable charge, because the distribution of log $\mathrm{K}_{\mathrm{H} \text {,app }}$ is wide due to the electrostatic interactions.

- $\sigma_{0}-\mathrm{pH}$ curves of variable charge colloids (metal oxides, organic colloids) can be interpreted in terms of an apparent-affinity distribution $f\left(\log \mathrm{K}_{\mathrm{H} \text {.app }}\right)$. The resulting distributions are in general a very poor presentation of the intrinsic-affinity distribution.

- The $\sigma_{\mathrm{o}}-\mathrm{pH}$ curves for a homogeneous amphoteric metal oxide, constructed on the basis of a one-pK model combined with a Stern-Gouy-Chapman double layer, lead to a bimodal distribution of apparent affinities. Hence, for an amphoteric surface a bimodal apparent-affinity distribution is not per se an indication for the applicability of a two-pK electrochemical model.

- The effect of an intrinsic-affinity distribution on the $\sigma_{\mathrm{o}}-\mathrm{pH}$ curves differs for random or patchwise heterogeneity.

- Acid (or basic) organic colloids are in general more sensitive for 'intrinsic heterogeneity' than (amphoteric) metal oxides.

- In the case of a strong heterogeneity the use of continuous distribution functions (like Gaussian or 'Sips') is to be preferred over the use of discrete distributions because of the (much) smaller number of parameters that is necessary to characterize the system.

\section{References}

Bolt, G. H., 1982. Theories of cation adsorption by soil constituents: Distribution equilibrium in electrostatic fields. In: G. H. Bolt (Ed.), Soil chemistry. B. Physico-chemical models, 2nd ed., p. 47-76. Elsevier, Amsterdam.

Bolt, G. H. \& W. H. van Riemsdijk, 1982. Ion adsorption on inorganic variable charge constituents. In: G. H. Bolt (Ed.), Soil chemistry. B. Physico-chemical models, 2nd ed., p. 459-504. Elsevier, Amsterdam. 
Bolt, G. H. \& W. H. van Riemsdijk, 1987. Surface chemical processes in soil. In: W. Stumm (Ed.), Aquatic surface chemistry, p. 127-164. Wiley Interscience, New York.

Cerofolini, G. F., 1974. Localized adsorption on heterogeneous surfaces. Thin Solid Films 23: 129-152.

Dzombak, D. A., W. Fish \& F. M. M. Morel, 1986a. Metal-humate interactions 1. Discrete ligand and continuous distribution models. Environmental Science and Technology 20: 669-675.

Dzombak, D. A., W. Fish \& F. M. M. Morel, 1986b. Metal-humate interactions 2. Application and comparison of models. Environmental Science and Technology 20: 676-683.

Ephraim, J. \& J. A. Marinsky, 1986. A unified physicochemical description of the protonation and metal ion complexation equilibria of natural organic acids (humic and fulvic acids). 1. Analysis of the influence of polyelectrolyte properties on protonation equilibria in ionic media: fundamental concepts. Environmental Science and Technology 20: 349-354.

Greenland, D. J. \& M. H. B. Hayes (Eds.), 1978. The chemistry of soil constituents. Wiley Interscience, Chichester, $714 \mathrm{pp}$.

Harding, I. H. \& T. W. Healy, 1985. Adsorption of aqueous cadmium (II) on amphoteric latex colloids I. General kinetics and thermodynamics. Journal of Colloid and Interface Science 107: 362-370.

Harris, L. B., 1968. Adsorption on a patchwise heterogeneous surface. I. Mathematical analysis of the step-function approximation to the local isotherm. Surface Science 10: 129-145.

Harris, L. B., 1969a. Adsorption on a patchwise heterogeneous surface. II. Heats of adsorption from the condensation approximation. Surface Science 13: 377-392.

Harris, L. B., 1969b. Adsorption on a patchwise heterogeneous surface. III. Errors incurred in using the condensation approximation to estimate the energy distribution on a Hill-De Boer adsorbent. Surface Science 15: 182-187.

Healy, T. W. \& C. R. White, 1978. Ionizable surface group models of aqueous interfaces. Advances in Colloid and Interface Science 9: 309-345.

Hiemstra, T., W. H. van Riemsdijk \& M. G. M. Bruggenwert, 1987. Proton adsorption mechanism at the gibbsite and aluminium oxide solid/solution interface. Netherlands Journal of Agricultural Science 35: $281-293$.

Holtzclaw, K. M., G. D. Schaumberg, C. S. LeVesque-Madore, G. Sposito, J. A. Herck \& C. T. Johhnston, 1980. Analytical properties of the soluble metal-complexing fractions in sludge-soil mixtures. V. Aminoacids, hexosamines, and other carbohydrates in fulvic acid. Soil Science Society of America Journal 44: 736-740.

House, W. A., 1983. Adsorption on heterogeneous surfaces. In: D. H. Everett (Ed.), Colloid science. Specialist Periodic Reports, Vol. 4, p. 1-58. Chemical Society, London.

House, W. A. \& M. J. Jaycock, 1977. Determination of the surface heterogeneity of solid particulates using the patchwise adsorption model. Journal of the Chemical Society Faraday Transactions I73: 942949.

House, W. A. \& M. J. Jaycock, 1978. A numerical algorithm for the determination of the adsorptive energy distribution function from isotherm data. Colloid and Polymer Science 256: 52-61.

Hunston, D. L., 1975. Two techniques for evaluating small molecule-macromolecule binding in complex systems. Analytical Biochemistry 63: 99-109.

Jaroniec, M., 1983. Physical adsorption or heterogeneous solids. Advances in Colloid and Interface Science 18: 149-225.

Jaroniec, M. \& W. Rudzinsky, 1975. Adsorption of gas mixtures on heterogeneous surfaces: the integral representation for a monolayer total adsorption isotherm. Surface Science 52: 641-652.

Koopal, L. K., W. H. van Riemsdijk \& M. G. Roffey, 1987. Surface ionization and complexation models: a comparison of methods for determining model parameters. Journal of Colloid and Interface Science 118: 117-136.

Koopal, L. K. \& C. H. W. Vos, 1985. Calculations of the adsorption energy distribution from the adsorption isotherm by singular value decomposition. Colloids and Surfaces 14: 87-95.

Müller, G., C. J, Radke \& J. M. Prausnitz, 1985. Adsorption of weak organic electrolytes from dilute aqueous solution onto activated carbon. Part I. Single-solute Systems. Journal of Colloid and Interface Science 103: 466.

Noble, B., 1977. The numerical solution of integral equations. In: D. Jacobs (Ed.), The state of the art in numerical analysis, p. 915-966. Academic Press, London. 


\section{HETEROGENEITY AND ELECTROLYTE ADSORPTION}

Papoulis, A., 1972. Probability, random variables, and stochastic processes, p. 103. McGraw-Hill, Tokyo.

Riemsdijk, W. H. van, G. H. Bolt \& L. K. Koopal, 1986a. Surface heterogeneity and electrolyte adsorption. Proceedings of the 2nd ISSS-NATO Workshop on Soil Colloid Surfaces, Ghent (in press).

Riemsdijk, W. H. van, G. H. Bolt, L. K. Koopal \& J. Blaakmeer, 1986b. Electrolyte adsorption on heterogeneous surfaces: adsorption models. Journal of Colloid and Interface Science 109: 219-229.

Riemsdijk, W. H. van \& S. E. A. T. M. van der Zee, 1986. Comparison of models for adsorption solid solution and surface precipitation. Proceedings of the 2nd ISSS-NATO Workshop on Soil Colloid Surfaces, Ghent (in press).

Riemsdijk, W. H. van, J. C. M. de Wit, L. K. Koopal \& G. H. Bolt, 1987. Metal ion adsorption on heterogeneous surfaces: adsorption models. Journal of Colloid and Interface Science 116: 511-522.

Sacher, R. S. \& I. D. Morrison, 1979. An improved CAEDMON program for the adsorption isotherms of heterogeneous substrates. Journal of Colloid and Interface Science 70: 153-166.

Shuman, M. S., B. J. Collins, P. J. Fitzgerald \& D. L. Olsen, 1983. Distribution of stability constants and dissociation rate constants among binding sites on estuarine copper-organic complexes; rotated disk electrode studies and an affinity spectrum analysis of ion selective electrode and photometric data. In: R. F. Christman and E. G. Gjessing (Eds.), Aquatic and terrestrial humic materials, p. 349-370. Ann Arbor Science Publishers, Ann Arbor, MI, USA.

Sips, R., 1948. On the structure of a catalyst surface I. The Journal of Chemical Physics 16: 490-495.

Sips, R., 1950. On the structure of a catalyst surface II. The Journal of Chemical Physics 18: 1024-1026.

Sposito, G., 1984. The surface chemistry of soils. Oxford University Press, New York, 234 pp.

Sposito, G., 1986. Sorption of trace metals by humic materials in soils and natural waters. CRC Critical Reviews in Environmental Control 16: 193-229.

Vos, C. H. W. \& L. K. Koopal, 1985. Surface heterogeneity analysis by gas adsorption; improved calculation of the adsorption energy distribution function using an algorithm named CAESAR. Journal of Colloid and Interface Science 105: 183-196.

Westall, J. \& H. Hohl, 1980. A comparison of electrostatic models for the oxide/solution interface. Advances in Colloid and Interface Science 12: 265-294.

Zee, S. E. A. T. M. van der \& W. H. van Riemsdijk, 1986. Transport of phosphate in a heterogeneous field. Transport in Porous Media 1: 339-359. 